Butler, M. \& Knight, B. C. J. G. (1960). J. gen. Microbiol. 22, 470-477

\title{
The Survival of Washed Suspensions of Mycoplasma
}

\author{
By M. BUTLER AND B. C. J. G. KNIGHT \\ Department of Microbiology, University of Reading
}

SUMMARY: Washed Mycoplasma organisms died rapidly when suspended in $0.85 \%(\mathrm{w} / \mathrm{v}) \mathrm{NaCl}$ prepared in laboratory 'distilled' water (steam condensate) at room temperature; this rapid killing was decreased by adding to the suspensions certain chelating agents, reducing agents or finely ground manganese dioxide. Washed organisms survived well in potassium phosphate $\left(\mathrm{K}_{2} \mathrm{HPO}_{4}, 0.01 \mathrm{M}\right.$ adjusted to $\left.\mathrm{pH} 7\right)$ dissolved in good quality 'deionized' water at $2-4$. ${ }^{\circ}$. The quality of the water used was very important.

Our colleague, the late Stuart Crowther, observed that the viability in laboratory saline of washed suspensions of Mycoplasma bovigenitalium (a bovine species in the pleuropneumonia-like group of micro-organisms; PPLO) which he was using to seed the surface of solid medium (Crowther \& Knight, 1956) decreased markedly during 1-2 hr. at room temperature $\left(c .20^{\circ}\right)$. The work reported here was an examination of conditions which affect the stability of suspensions of Mycoplasma. Conditions were eventually found for the preparation of washed Mycoplasma suspensions (containing measured numbers of viable particles) which were relatively stable and suitable as inocula for exact nutritional studies.

\section{METHODS}

Organisms. Mycoplasma bovigenitalium (PG 12); $M$. laidlawii strain A (PG 8); M. mycoides var. mycoides (PG 1) (nomenclature of Edward \& Freundt, 1956). The cultures were kindly given by Dr D. G. ff. Edward (The Wellcome Research Laboratories, Beckenham, Kent).

Culture medium. The medium devised by Edward (1947) was used slightly modified (Edward \& Fitzgerald, 1951, 1952; Butler \& Knight, 1960b) and will be referred to as Edward medium; it was solidified when required for colony counting by adding $2 \%(\mathrm{w} / \mathrm{v})$ agar-agar, Japanese shredded (British Drug Houses Ltd.); this was the brand of agar-agar eventually chosen (see below).

Water. (1) Laboratory 'distilled' water (steam condensate; SC water) was obtained from a Manesty still (type 000; Manesty Machines Ltd., Liverpool) working from the laboratory steam supply.

(2) Glass-distilled (GD) water was obtained by redistilling SC water in an all Pyrex-glass apparatus.

(3) Deionized (DM) water was obtained from a Mark III portable Deminrolit Plant (Permutit Co., Ltd., London, W. 4).

(4) High quality (HQ) deionized water (specific conductivity c. $4 \times 10^{6}$ ohms./cm.) was obtained from an Elgastat portable deionizer (type B 102; Elga Products Ltd.: London, S.W. 19). 
Waters 1, 2 and 3 were sterilized by autoclaving for $20 \mathrm{~min}$. at $121^{\circ}$. Water 4 (HQ) was sterilized by suction through a sintered glass filter.

Glassware. Pyrex-glass vessels were used for growing cultures; they were cleaned with chromic + sulphuric acid mixture and thoroughly rinsed with SC water. For experiments with $\mathrm{HQ}$ water the vessels were also rinsed with $\mathrm{HQ}$ water.

Conditions of cultivation. Stock cultures in liquid Edward medium were grown in 6 in. $\times \frac{5}{8}$ in. test tubes incubated, vertically, in air at $37^{\circ}$ without agitation. The organisms were subcultured every 4 or 5 days by pipetting $0 \cdot 1 \mathrm{ml}$. culture into $10 \mathrm{ml}$. sterile medium. To obtain organisms for experiments, Edward medium (10-70 ml., as required) in test tubes (capacity $\boldsymbol{c}$. $15-100 \mathrm{ml}$.) was inoculated by adding $1 \%(\mathrm{v} / \mathrm{v})$ stock culture and incubating statically in air for $24 \mathrm{hr}$. at $37^{\circ}$.

Preparation of suspensions of washed organisms. After preliminary experiments the following method for harvesting and washing the organisms was chosen. Five ml. of a $24 \mathrm{hr}$. culture (containing $c .1 \times 10^{9}$ viable particles $/ \mathrm{ml}$.) were transferred to a $10 \mathrm{ml}$. Pyrex-glass centrifuge tube and centrifuged at $2400 \mathrm{~g}$ for $30 \mathrm{~min}$. at $2-4^{\circ}$. The supernatant fluid was removed and the deposit suspended in $5 \mathrm{ml}$. potassium phosphate solution $\left(\mathrm{K}_{2} \mathrm{HPO}_{4}, 0.01 \mathrm{~m}\right.$ in GD water; adjusted to $\mathrm{pH} 7$ with $\mathrm{N}-\mathrm{HCl}$ ) held at $2-4^{\circ}$, by pipetting in the washing fluid, closing the centrifuge tube with a rubber bung and shaking vigorously for about 30 sec. This suspension was again centrifuged in the cold as above, the supernatant fluid decanted and the deposit of washed organisms suspended in $5 \mathrm{ml}$. of a chosen suspending medium. In the sequel 'washed organisms' means organisms washed as just described.

The colony count of Mycoplasma suspensions. The colony count method of Miles \& Misra (1938) was used as described below. This method of plating by depositing drops of dilution on a nutrient agar surface is very convenient for Mycoplasma because the colonies are small (rarely greater than $1 \mathrm{~mm}$. diameter) and, even when they touch, the different colonies can easily be distinguished by a characteristic central dark spot when viewed by a low-power microscope (Butler \& Knight, 1956).

Solid Edward medium in Petri dishes was dried by opening the plates in a hot room $\left(37^{\circ}\right)$ for 2-3 hr. Serial decimal dilutions of samples of suspensions of organisms were made in potassium phosphate $\left(\mathrm{K}_{2} \mathrm{HPO}_{4}, 0.01 \mathrm{M}\right)$ in DM water $+1 \%(\mathrm{v} / \mathrm{v})$ liquid Edward medium, adjusted to $\mathrm{pH} 8$ with $\mathrm{N}-\mathrm{NaOH}$. Three drops of each dilution were placed by dropping-pipette (delivering $0.02 \mathrm{ml}$./ drop) on the surface of the dried agar; each drop spread to form a circular patch c. $15 \mathrm{~mm}$. diameter. It was possible to place three separated drops on each quadrant of the plate; thus drops in triplicate from four dilutions could be placed on one plate. The drops were allowed to dry and the inoculated plates incubated at $37^{\circ}$ in closed tins to prevent further drying of the medium. After incubation for 3 days the colonies were counted by using a stereoscopic microscope (magnification $\times 6 \cdot 25$; Watson $\&$ Sons Ltd., London, W.C. 1) fitted with an eye-piece graticule ruled in $1 \mathrm{~mm}$. squares. It was possible to count up to c. 500 colonies/drop area. 
The diluent. It was found essential to use a suitable diluent for the colony count with these Mycoplasma organisms, otherwise there were uncontrollable decreases in count. Ordinary laboratory saline $(\mathrm{NaCl} 0.85 \%, \mathrm{w} / \mathrm{v}$, in $\mathrm{SC}$ water) was toxic at room temperature for Mycoplasma bovigenitalium, $\boldsymbol{M}$. laidlawii and $M$. mycoides var. mycoides. This toxicity was removed by adding $1 \%(\mathrm{v} / \mathrm{v})$ liquid Edward medium. One \% (v/v) Edward medium in GD or DM water were equally good diluents; undiluted liquid Edward medium was no better. Potassium phosphate $\left(\mathrm{K}_{2} \mathrm{HPO}_{4} ; 0.01 \mathrm{M}\right)$ was added to the $1 \%(\mathrm{v} / \mathrm{v})$ Edward medium in DM water because the $\mathrm{pH}$ value of the DM water varied; the buffered dilute Edward medium was adjusted to $\mathrm{pH}$ 8. This diluent was used unsterilized since it was found that when freshly prepared very few contaminating bacteria grew out on the solid Edward medium (containing thallium acetate) used for the colony count. The colony count of organisms kept in this diluent at room temperature did not significantly change during $10 \mathrm{~min}$., which was long enough for making and using dilutions from one sample for the colony count.

The reliability of the colony counting method was examined for conformity with a Poisson distribution by the $\chi^{2}$ test (Fisher, 1946) and was found to be satisfactory. The coefficient of variation of the colony count was $15.7 \%$. A test was made to see whether the viable particles in the original suspension broke up into more numerous viable particles during the dilution procedure. The colony counts of two consecutive decimal dilutions of cultures of Mycoplasma bovigenitalium, $\boldsymbol{M}$. laidlawii and $\boldsymbol{M}$. mycoides var. mycoides, respectively, were compared and found to be very near to the expected decimal relationship.

\section{RESULTS}

The nature of the nutrient agar surface in plating: some inhibitory effects

In preliminary work on the cultivation of Mycoplasma bovigenitalium we observed on one occasion that no growth occurred on surface-inoculated Edward medium agar except round small heaps of manganese dioxide $\left(\mathrm{MnO}_{2}\right)$; no satellite colonies occurred round heaps of soluble starch or diatomaceous earth. In subsequent experiments growth occurred more generally on the surface of the medium, although round heaps of $\mathrm{MnO}_{2}$ the colonies were still more numerous. The agar-agar used for solidifying the medium used in this particular experiment was different from that now used (which is Japanese shredded, British Drug Houses Ltd.). Growth of surface-inoculated organisms was inhibited by $3 \%(\mathrm{w} / \mathrm{v})$ hydrogen peroxide added as drops $(0.02 \mathrm{ml}$.) to the surface of the medium. The zone of growth inhibition was greatly decreased when finely ground $\mathrm{MnO}_{2}$ was incorporated in the medium. The toxic effect of media solidified by certain samples of agar-agar (our preliminary experiments; compare Proom, Woiwood, Barnes \& Orbell, 1950) was not operative in the later experiments now reported.

The addition of $1-5 \%(v / v)$ of a solution of lysed red blood cells (red cells from $10 \mathrm{ml}$. horse blood lysed with $20 \mathrm{ml}$. distilled water, and the lysed solution clarified by centrifugation) neither increased the size nor the number of 
colonies of Mycoplasma bovigenitalium grown on solid Edward medium prepared with the Japanese shredded B.D.H. agar as described. We now always test media solidified with new batches of agar-agar by adding lysed red cells to see whether or not the count is altered by so doing. When the count is not increased we accept the medium as satisfactory.

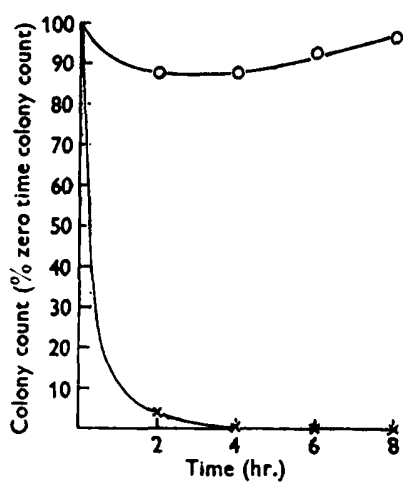

Fig. 1

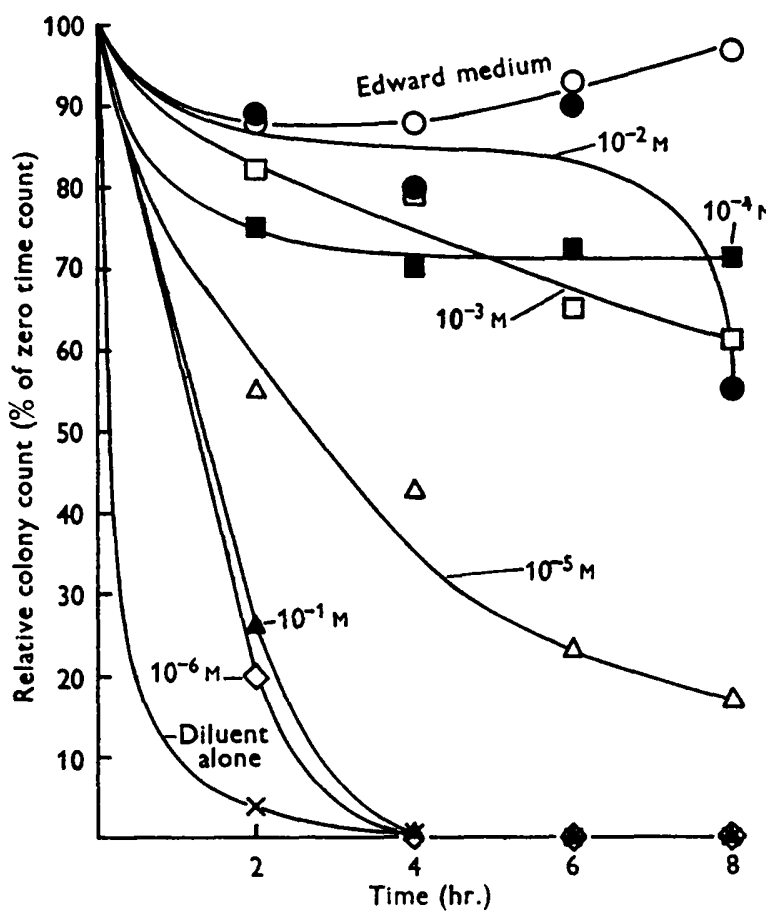

Fig. 2

Fig. 1. The survival of washed Mycoplasma bovigenitalium at room temperature in different media. Edward medium, $-\mathrm{O}-$; potassium phosphate $\left(\mathrm{K}_{2} \mathrm{HPO}_{4}, 0.01 \mathrm{M}\right)+$ sucrose $(0.25 \mathrm{M})$ in GD water (adjusted to $\mathrm{pH} 7),-\times-$. The other suspending media mentioned in the text gave similar decreases in count.

Fig. 2. The survival of washed Mycoplasma bovigenitalium at room temperature in different media. Edward medium, $-\mathrm{O}-$. Potassium phosphate $\left(\mathrm{K}_{2} \mathrm{HPO}_{4}, 0.01 \mathrm{M}\right)+$ sucrose $(0.25 \mathrm{M})$ in GD water (adjusted to $\mathrm{pH} 7$ ), other curves. Different concentrations ( $\mathrm{M}$ ) of sodium diethyldithiocarbamate added are marked on the diagram.

The survival of suspensions of rwashed Mycoplasma at room temperature

The survival of washed Mycoplasma bovigenitalium (initially containing c. $5 \times 10^{8}$ viable particles $/ \mathrm{ml}$.) at room temperature $\left(c .20^{\circ}\right)$ was very poor in: $0.85 \%(\mathrm{w} / \mathrm{v}) \mathrm{NaCl}$ in GD water; Krebs-Ringer phosphate in GD water (adjusted to $\mathrm{pH} \mathrm{7}$ ); GD water alone; potassium phosphate $\left(\mathrm{K}_{2} \mathrm{HPO}_{4}, \mathbf{0 . 0 1} \mathrm{M}\right)+$ sucrose $(\mathbf{0 \cdot 2 5} \mathrm{M})$ in GD water (adjusted to $\mathrm{pH} 7$ ). Washed organisms resuspended in Edward medium always survived well. Figure 1 illustrates this, comparing Edward medium with dilute potassium phosphate + sucrose in GD water.

Effect of certain chelating agents, reducing agents, and manganese dioxide. The survival of washed Mycoplasma in $\mathrm{NaCl}$ in GD water, Krebs-Ringer phosphate 
in GD water, phosphate + sucrose in GD water and in GD water alone was greatly improved when certain chelating agents were added to the solutions. This effect was further examined for washed organisms in phosphate + sucrose in GD water (subsequently it was found that the sucrose was unnecessary). The chelating agents tested were sodium diethyldithiocarbamate, ethylenediamine tetra-acetic acid and 8-hydroxyquinoline. The concentration of added

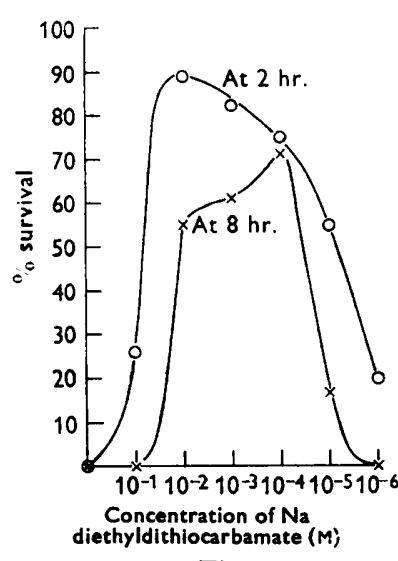

Fig. 3

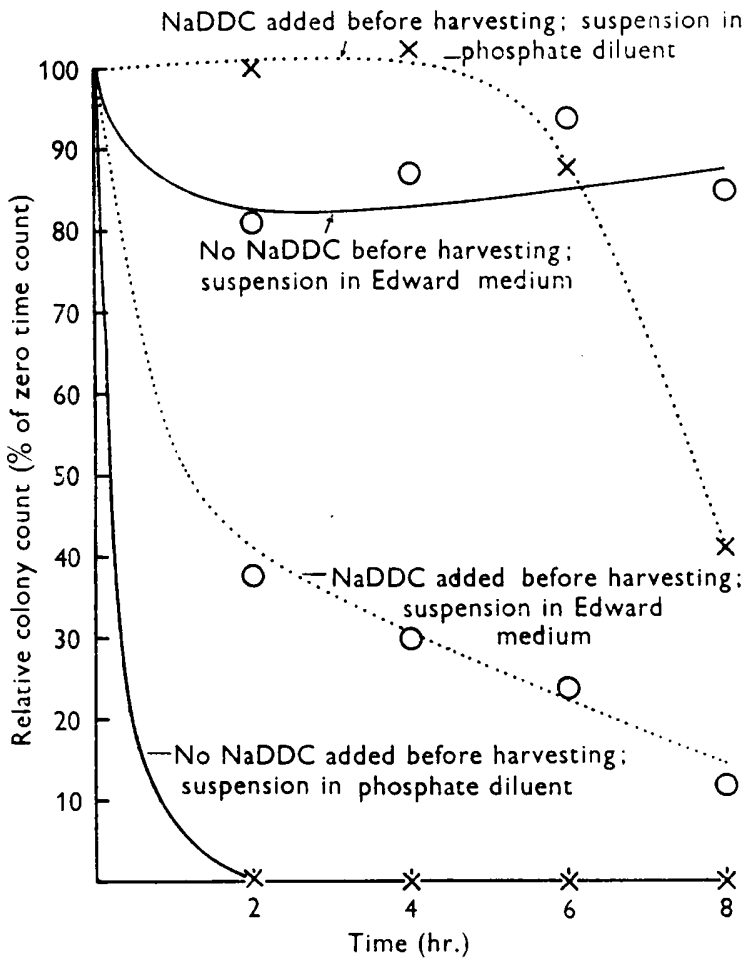

Fig. 4

Fig. 3. The survival of washed Mycoplasma bovigenitalium at room temperature in potassium phosphate $\left(\mathrm{K}_{2} \mathrm{HPO}_{4}, 0.01 \mathrm{M}\right)+$ sucrose $(0.25 \mathrm{M})$ + sodium diethyldithiocarbamate $(\mathrm{M})$ in GD water (adjusted to pH 7). Survival: at $2 \mathrm{hr} .,-\mathrm{O}-$ at $8 \mathrm{hr}$., $-\times-$.

Fig. 4. Effect of adding $\mathrm{Na}$ diethyldithiocarbamate $\left(10^{-8} \mathrm{M}\right)$ to a culture before harvesting, on the survival of washed Mycoplasma bovigenitalium at room temperature. Survival: in Edward medium, $\cdots O \cdots$; in potassium phosphate $\left(\mathrm{K}_{2} \mathrm{HPO}_{4}, \mathbf{0 . 0 1} \mathrm{M}\right)+$ sucrose $(0.25 \mathrm{M})$ in GD water (adjusted to $\mathrm{pH} \mathbf{7}), \cdots \times \cdots$. The survival in these media of organisms harvested normally, i.e. from cultures without added NaDDC, is indicated by same symbols but solid lines; see also Fig. 1 .

chelating agents was found to be important. The effects of added $\mathrm{Na}$ diethyldithiocarbamate are shown in Fig. 2 which shows that there was an optimal concentration, survival being less good at higher and lower concentrations. The optimal concentrations for survival at 2 and $8 \mathrm{hr}$. at room temperature were c. $10^{-2}$ and $10^{-4} \mathrm{M}$, respectively (Fig. 3). Families of curves similar to those illustrated in Fig. 2 were obtained with ethylenediamine tetra-acetate and 8-hydroxyquinoline. The colony count at the optimal concentration $\left(c .10^{-4} \mathrm{M}\right)$ 
of these chelating agents after $8 \mathrm{hr}$. at room temperature was about $70 \%$ of the initial count.

The survival of washed organisms in phosphate + sucrose in GD water was somewhat improved when sodium sulphite $\left(\mathrm{Na}_{2} \mathrm{SO}_{3}\right)$ was added; the colony count at the optimal concentration $(c .0 .4 \mathrm{M})$ after $8 \mathrm{hr}$. at room temperature was c. $20 \%$ of the initial count. The addition of manganese dioxide $\left(\mathrm{MnO}_{2}\right.$; finely ground so that some stayed in suspension during the experiment) markedly improved the survival of washed organisms in phosphate + sucrose in $\mathrm{GD}$ water at room temperature. The concentration of $\mathrm{MnO}_{2}$ was not critical, being equally effective when added at $0.025,0.25$ and $2.5 \%(w / v)$. The colony count after $8 \mathrm{hr}$. at room temperature was still c. $10 \%$ of the initial count; without $\mathrm{MnO}_{2}$ similar suspensions of washed organisms would have been effectively sterile some $2-4 \mathrm{hr}$. after preparation.

$\mathrm{Na}$ diethyldithiocarbamate, ethylenediamine tetra-acetate or manganese dioxide when added to suspensions of washed organisms (containing c. $5 \times 10^{8}$ viable particles $/ \mathrm{ml}$.) of Mycoplasma laidlawii or $\boldsymbol{M}$. mycoides var. mycoides in phosphate + sucrose in GD water annulled the toxicity of this medium in a way similar to that described for $\boldsymbol{M}$. bovigenitalium.

When $\mathrm{Na}$ diethyldithiocarbamate $(0.001 \mathrm{M})$ was added to a culture of Mycoplasma bovigenitalium just before it was harvested, the washed organisms prepared from this culture survived much better when suspended in phosphate + sucrose in GD water (Fig. 4), than did organisms which were obtained from normal cultures harvested in the usual way (i.e. without the addition of chelating agent; Fig. 1). However, $60 \%$ of the washed organisms from NaDDCtreated cultures died within $2 \mathrm{hr}$. when they were placed in Edward medium (Fig. 4), whereas washed organisms from normal cultures survived very well (Fig. 1).

Effect of some other compounds. The effect of some other compounds on washed Mycoplasma bovigenitalium in phosphate + sucrose in GD water was also tested. The addition of dimercaptopropanol (c. $0.002 \mathrm{M})$, cysteine $(0.001 \mathrm{M})$, $p$-phenylenediamine $(0.001 \mathrm{M})$ gave colony counts after $8 \mathrm{hr}$. at room temperature which were $c .40,15$ and $1 \%$, respectively, of the initial count. Ascorbic acid $(0.001 \mathrm{M})$ was very toxic towards washed organisms in phosphate + sucrose in GD water.

\section{The survival of washed suspensions of Mycoplasma at 2-4 ${ }^{\circ}$}

An inoculum of washed Mycoplasma sufficient to give an initial colony count of $c .10^{4}$ viable particles $/ \mathrm{ml}$. in liquid media was thought desirable for the study of the exact nutritional requirements of Mycoplasma in order to allow, in conditions of optimal growth, a $10^{4}$ - to $10^{5}$-fold multiplication. For this purpose a suspension of washed organisms which contained $c .10^{6}$ viable particles $/ \mathrm{ml}$. was required for use as the inoculum, to be added at $0 \cdot 1 \mathrm{ml} . / 10 \mathrm{ml}$. medium.

The use of a chelating agent in the suspending medium of the washed organisms was eventually concluded to be inadvisable because of the difficulty of controlling its effect. The survival of washed organisms in potassium phosphate $\left(\mathrm{K}_{2} \mathrm{HPO}_{4}, 0.01 \mathrm{M}\right)$ in $\mathrm{DM}$ water (adjusted to $\mathrm{pH} 7$ ) was therefore examined 
at less than room temperature. While at room temperature these suspensions were effectively sterile within $15-30 \mathrm{~min}$., at 2-4 $4^{\circ}$ the organisms survived for 1-2 hr., but the degree of survival varied from experiment to experiment. This irregularity may have been due to differences in the quality of the DM water, which varied from a specific conductivity $c .5 \times 10^{5}$ to $3 \times 10^{4} \mathrm{ohms} / \mathrm{cm}$., depending on the time of sampling after regeneration of the demineralizing plant. To avoid these irregularities the phosphate solution was then prepared in HQ water (specific conductivity $c .4 \times 10^{6} \mathrm{ohms} / \mathrm{cm}$.). The $\mathrm{pH}$ value of this solution was important; $\mathrm{pH} 7$ was optimal. At this $\mathrm{pH}$ value the number of viable washed particles did not change significantly during $1 \mathrm{hr}$. at $2-4^{\circ}$.

As a result of the foregoing experiments it is concluded that a suitable diluent for the routine washing and suspension of Mycoplasma organisms, when freedom from materials carried over from the complex Edward medium is desired, would be potassium phosphate $\left(\mathrm{K}_{2} \mathrm{HPO}_{4} ; 0.01 \mathrm{M}\right)$ in $\mathrm{HQ}$ water (adjusted to $\mathrm{pH} 7$ ) held at 2-4.

\section{DISCUSSION}

Some aspects of the problem we have studied, i.e. to provide a relatively stable suspension of viable washed Mycoplasma organisms, were examined by Smith \& Sasaki (1958) with other strains of Mycoplasma. Our observations that washed organisms were much less sensitive to the toxicity of suspending media when held at $2-4^{\circ}$ and survived better at that temperature, agree with those of Smith \& Sasaki (1958). These authors also showed that the organisms were relatively insensitive to osmotic pressure changes; our organisms survived well in the dilute buffer at $2-4^{\circ}$.

Our observations about the toxicity of the suspending fluids, the effects of different qualities of water and the use of various adjuvants (e.g. chelating agents) are analogous to those of Kaufman \& Weaver (1958) for Clostridium perfringens ( $C$. welchii). These workers suggested that the various adjuvants which prevented decreases in colony count of suspensions of washed $C$. perfringens in saline acted as chelating agents to fix traces of toxic cations. From our work, although no direct evidence is available, it also seems likely that metal ions were concerned with the death of the washed Mycoplasma organisms, because chelating agents helped under certain conditions to maintain the viability of these suspensions. It was difficult to control conditions so that only toxic effects were annulled by chelating agents, because the organisms appeared to absorb these compounds, and when a sufficient amount was absorbed the subsequent growth of the organisms was delayed or prevented, perhaps by a too efficient binding of metal ions required for growth.

The protection of suspensions of washed organisms afforded by certain reducing agents and by $\mathrm{MnO}_{2}$ lends support to the idea that the toxicity was at some stage due to the presence of hydrogen peroxide. This might also explain the toxic action of ascorbic acid, which is known to autoxidize with the formation of hydrogen peroxide. Our observations that hydrogen peroxide was toxic for Mycoplasma bovigenitalium is in agreement with Warren (1942) who observed that hydrogen peroxide in serum broth inhibited growth of certain 
Mycoplasma strains. Our findings that the growth of Mycoplasma on the surface of some media was poor agree with observations of Lynn \& Morton (1956); they found that the inhibitory action of certain batches of agar was not removed by adding starch to the medium, heating the medium with $2 \%$ packed red blood cells or by extracting the agar with ether and methanol. Liebermeister (1954) also encountered similar difficulties with certain agar preparations. In our experiments the addition of lysed red cells (unheated) abolished the toxic effect of certain agar surfaces; we think this was because the red cell catalase destroyed hydrogen peroxide produced by components of the agaragar used (cf. Proom et al. 1950). Some specimens of agar-agar are worse than others in producing this inhibition of colony growth. The use of high quality 'deionized' water for making up the washing and suspending fluid, and working at low temperature $\left(2-4^{\circ}\right.$ ), would appear to limit the rate and extent of peroxide formation and action.

A grant from the Agricultural Research Council in support of this work is gratefully acknowledged.

\section{REFERENCES}

Butler, M. \& Knight, B. C. J. G. (1956). Growth curves of strains of pleuropneumonia-like organisms. J. gen. Microbiol. 14, vi.

Butuer, M. \& Knight, B. C. J. G. $(1960 \mathrm{~b})$. The measurement of the growth of Mycoplasma in liquid media. J. gen. Microbiol. 22, 478.

Crowther, S. \& Knight, B. C. J. G. (1956). The effect of nucleic acid fragments on the growth of a pleuropneumonia-like organism. J. gen. Microbiol. 14, vii.

EDWARD, D. G. FF. (1947). A selective medium for pleuropneumonia-like organisms. J. gen. Microbiol. 1, 238.

Edward, D. G. FF. \& Fitzgerald, W. A. (1951). Cholesterol in the growth of organisms of the pleuropneumonia group. J. gen. Microbiol. 5, 576.

Edward, D. G. FF. \& Fitzgerald, W. A. (1952). A growth factor needed to isolate organisms of the pleuropneumonia group from the genital tract of cattle. Vet. Rec. 64, 395.

Edward, D. G. FF. \& Freundt, E. A. (1956). The classification and nomenclature of organisms of the pleuropneumonia group. J. gen. Microbiol. 14, 197.

Fisher, R. A. (1946). Statistical Methods for Research Workers, 10th ed. London and Edinburgh: Oliver and Boyd.

KaUfman, L. \& Weaver, R. H. (1958). The preparation and maintenance of viable suspensions of Clostridium perfringens. Bact. Proc. G. 7, p. 28.

Liebermeister, K. (1954). Ein Nährsubstrat zur Züchtung von Organismen der Pleuropneumonia (PPLO) Gruppe. Z. Hyg. InfektKr. 140, 132.

Lynn, R. J. \& Morton, H. E. (1956). The inhibitory action of agar on certain strains of pleuropneumonia-like organisms. Appl. Microbiol. 4, 339.

Miles, A. A. \& Misra, S. S. (1938). The estimation of the bactericidal power of the blood. J. Hyg., Camb. 38, 732.

Proom, H., Woiwod, A. J., Barnes, J. M. \& Orbell, W. G. (1950). A growth-inhibitory effect on Shigella dysenteriae which occurs with some batches of nutrient agar and is associated with the production of peroxide. J. gen. Microbiol. 4, 270.

SmIth, P. F. \& SASAKI, S. (1958). Stability of pleuropneumonia-like organisms to some physical factors. Appl. Microbiol. 6, 184 .

WARREN, J. (1942). Observations on some biological characteristics of organisms of the pleuropneumonia group. J. Bact. 43, 211.

(Received 22 September 1959) 